Research Article

iMedPub Journals

www.imedpub.com

Vol.8 No.6:70

DOI: $10.4172 / 1989-8436.100070$

\section{In vivo Antimicrobial Activity of Ozonized Theobroma Oil Ovules against Candida albicans}

\section{Abstract}

Title: Effects of ozonated theobroma oil and ketoconazole ovules on rats infected with Candida albicans.

Background: Candidiasis is an infection caused by a yeast shaped fungus which includes Candida gender. Candida albicans is an opportunistic microorganism, which causes more than $80 \%$ of vaginal infections. The aim of this study was to determine the effect of ozonized theobroma oil vaginal ovules in the treatment of induced vaginal candidiasis compared to Ketoconazole ovules in Sprague Dawley female rats.

Methods and Findings: Animals were ovariectomized and injected with a hormonal treatment after 14 days in order to know the oestrus cycle. After 48 hours rats with keratinous cellules were vaginally infected with an inoculum of $10^{6}-10^{7}$ Candida albicans in $0.1 \mathrm{~mL}$ of phosphate buffer solution. Five animals groups were studied: group I (without treatment), group II (treated with unozonized theobroma oil ovules), group III (treated with ketoconazole ovules), group IV (treated with 10\% ozonized theobroma oil ovules), and group V (treated with $20 \%$ ozonized theobroma oil ovules). Exudates were made before beginning the treatment, 5 and 10 days during the treatment and 48 hours after the end of treatment. Results demonstrated a decrease of $0.7 \mathrm{log}$ of the number of rats with infection after 5 days of treatment with $20 \%$ ozonized theobroma oil ovules; however, it was not observed infection in rats after 10 days. A similar result was obtained with ketoconazole ovules.

Conclusions: Due to antimicrobial activity of $20 \%$ ozonized theobroma oil ovules, it can be recommended their use for treatment of Candidiasis

Keywords: Candida albicans; Candidiasis; Ketoconazole; Ovules; Ozonized theobroma oil; Sprague-Dawley female rats

Received: December 13, 2017; Accepted: December 18, 2017; Published: December 25, 2017

\section{Introduction}

Candidiasis is an infection caused by a yeast shaped fungus of family Cryptococacea, which also includes several types as Torulopsis, Trichosporum, Cryptococcus and Candida. Candida albicans is a saprophyte germ of normal microbiota of humans and other hot blood animals. It is an opportunistic microorganism, which causes more than $75 \%$ of the vaginal infections $[1,2]$. Treatment of these fungal infections is fundamentally based on polienes and some other imidazol derivative drugs. However,

\author{
Mari , Meneau RI ${ }^{2}$, \\ Fernández $\mathrm{I}^{3}$, Sánchez $\mathrm{Y}^{4 *}$ and \\ García G5 \\ 1 School of Chemistry and Pharmacy, \\ Andres Bello University, PO Box 832 \\ 0000, Santiago, Chile \\ 2 Science Institute of Materials \\ Technology, Havana University, PO Box \\ 10 400, Vedado, Havana, Cuba \\ 3 National Center for Scientific Research, \\ Ozone Research Center PO Box 6414, \\ Cubanacán, Playa, Havana, Cuba \\ 4 Center for the State Control of Drug \\ Quality, 5th A and 60 Street, Playa, \\ Havana, Cuba \\ 5 Pharmacy and Foods Institute, Havana \\ University, 222 Street, No. 2317, La Lisa, \\ PO Box 13600, C. Habana, Cuba
}

*Corresponding author:

Maritza F Díaz Gómez

झmaritza.diaz@unab.cl

Associate Professor, School of Chemistry and Pharmacy, Andres Bello University.

Tel: +56944413335

Citation: Maritza FD, Meneau RI, Fernández I, Sánchez Y, García G (2017) In vivo Antimicrobial Activity of Ozonized Theobroma Oil Ovules against Candida albicans. Arch Clin Microbiol. Vol.8 No.6:70 
that some ozonized vegetable oils, as sunflower, olive and theobroma oils showed antibacterial activity in vitro against several microorganisms $[8,9]$ and peroxidical compounds present in ozonized vegetable oil were responsible for antimicrobial activity [10-12]. On the other hand, preliminary studies with ozonized theobroma oil in vivo demonstrated satisfactory results [13].

Theobroma oil or cocoa butter is a solid fat with a melting point ranged between 32 and $35^{\circ} \mathrm{C}$. This product is highly demanded because of its suitable properties for chocolate manufacture. At room temperature, it is hard and brittle giving chocolate its snapping characteristics, but it also has a steep melting curve with complete melting at human body temperature. This property gives a cooling sensation and a smooth creamy texture; for example, the content of solids falls from 45 to $1 \%$ between 30 and $35^{\circ} \mathrm{C}$. The hardness of theobroma oil is related to its solid fat content at 20 and $25^{\circ} \mathrm{C}$ [14]. This melting behavior is related to the chemical composition of theobroma oil. This oil is rich in palmitic (24-30\%), stearic (30 to $36 \%$ ), and oleic acids (32-39\%) and its major triacylglycerol are of the kind SOS, where $S$ represents saturated acyl chains in the 1 and 3 positions and $O$ represents an oleyl chain in the 2 positions. Cocoa butter has a high content of saturated acids that raises health risks, but it has been argued that most of these saturated acids is the noncholesterolemic stearic acid [15]. According to composition and physical characteristics of the theobroma oil, suitable properties for preparing some pharmaceutical formulations from ozonized theobroma oil could be expected [16]. The aim of this study was to determine the effect of ozonized theobroma oil vaginal ovules in the treatment of the induced vaginal candidiasis compared with Ketoconazole ovules in Sprague Dawley female rats.

\section{Materials and Methods}

Forty female Sprague Dawley rats (180-200 g) were purchased from the National Centre for Laboratory Animals Production (Cuba). Animals were maintained in quarantine in an air-filtered and temperature-conditioned room $\left(20 \pm 2^{\circ} \mathrm{C}\right)$ with a relative humidity of $50 \pm 5 \%$. Rats were fed with standard laboratory chow and water ad libitum and were kept under an artificial light/ dark cycle of 12 hours [17]. This was carried out according to the ethical guidelines for the research with laboratory animals and was approved by the Ethical Committee of Animal Experiments of the National Centre for Scientific Research, Havana City, Cuba.

Starting from Candida albicans ATCC 10231 on Sabouraud Dextrose Agar plates, it was prepared a suspension of $0.1 \mathrm{~mL}$ with $10^{6}-10^{7} \mathrm{CFU} / \mathrm{mL}$ concentration on phosphate buffer sterile (PBS). Vaginal sweats were performed by washing with $0.2 \mathrm{~mL}$ of PBS. Subsequently $0.05 \mathrm{~mL}$ of fluid obtained were seeded on Sabouraud Dextrose Agar. Incubation was for $48 \mathrm{~h}$ at $30^{\circ} \mathrm{C}$.

Sprague-Dawley female rats were ovariectomized. Vaginal sweats were performed after 14 days to determinate oestrus cycle and the presence of Candida albicans. All rats had an injection with hormonal treatment. After 48 hours only the rats with keratinous cellules were vaginally infected by an inoculum of $10^{6}-10^{7}$ Candida albicans in $0.1 \mathrm{~mL}$ of phosphate buffer solution. Four days later, a new vaginal sweat was carried out to determine the infection level. They were considered as infected those rats with more to $10^{2} \mathrm{CFU} / \mathrm{mL}$ of infection.

Five groups of infected animals were studied: Group I (without treatment); Group II (treated with unozonized ovules); Group III (treated with ketoconazole ovules); Group IV (treated with $10 \%$ ozonized theobroma oil ovules); Group V (treated with $20 \%$ ozonized theobroma oil ovules).

One daily ovules was applied. Exudates were made before beginning of the treatment, at fifth day of the treatment, at tenth day of the treatment and 48 hours after the end of treatment.

Theobroma oil was supplied by "Rubén David Suárez Abella" company of Cuba. Ovules with theobroma oil and ozonized theobroma oil at 10 and $20 \%$ with vehicle in enough quantity for a $100 \%$, were elaborated in the Ozone Research Centre with approximate values of peroxide index between 110 and 220 mmol-equiv of active $\mathrm{O}_{2} / \mathrm{kg}$ of sample, respectively.

Ketoconazole ovules 400 mg L-0705, was supplied by "Roberto Escudero" pharmaceutical laboratory, Havana, Cuba.

Estradiol of Depósito $10 \mathrm{mg} / 1 \mathrm{~mL}$ Lote 07001 and Sódico Tiopental $500 \mathrm{mg}$. Liofilizado. L-6004 were supplied by Quimefa Company of Cuba.

For each group of rats studied, the logarithm in base 10 of the number of microorganisms $(\log N)$ as a function of time $(0,5$, 10 and 12 days) was calculated to normalize the distribution. These values were summed and averaged for each group and normalized to be able to correctly interpret the results.

\section{Results and Discussion}

Four animals perished during surgery. Thirty-three rats were selected to carry out the experience (Candida albicans inoculation), because the vaginal mucous showed estro characteristics and did not present Candida albicans infection.

During infection process, 30 animals achieved infection levels superior to $10^{2} \mathrm{CFU} / \mathrm{mL}$ (Table 1), thus it is considered that these animals are infected, which allowed the establishment of the effectivity in a $90 \%$, which is a higher value than the $80 \%$ obtained by an experimental model published.by Lezcano et al. [13].

Five days after the beginning of the treatment, it could be observed that in group I (without treatment), a single animal showed Candida albicans concentrations lower than $10^{2} \mathrm{CFU}$, while in group II (treated with unozonized formulation) two animals exhibited this very same behavior. Sobel et al. [18] reported the spontaneous elimination of the disease in $10 \%$ of infected rats, thus these results can be attributed to the characteristics

Table 1 Infection Process

\begin{tabular}{|c|c|c|}
\hline Infected rats & Candida albicans (CFU/mL) & (\%) \\
\hline $3 / 33$ & $10^{4}-10^{5}$ & 9.1 \\
\hline $10 / 33$ & $10^{3}-10^{4}$ & 30.3 \\
\hline $17 / 33$ & $10^{2}-10^{3}$ & 51.5 \\
\hline $3 / 33$ & $10-10^{2}$ & 9.1 \\
\hline
\end{tabular}


of the model as well as defense mechanisms inherent to vaginal mucous. Regarding group III treated with ketoconazole, it can be observed that at fifth day none of the animals is infected, since three of them showed no Candida albicans at all and two animals exhibited Candida albicans concentrations lower than $10^{2} \mathrm{CFU}$. In group IV (treated with $10 \%$ ozonized theobroma oil ovules), they were found three animals with Candida albicans concentrations lower than $10^{2} \mathrm{CFU}$, in addition number of microorganisms decreased in a $31 \%$. On the other hand, in group $V$ (treated with $20 \%$ ozonized theobroma oil ovules), none of the animals showed Candida concentrations superior to $10^{2} \mathrm{CFU}$, thus, it can be claimed that the $20 \%$ ozonized theobroma formulation removed the infection in every treated animal of this study.

Ten days after the treatment begun group I (without treatment) and group II (treated with unozonized formulation) showed a decrease of the number of microorganisms lower than $25 \%$, plus, every animal in both groups remained infected but a single animal of group II, which showed Candida concentrations lower than $10^{2} \mathrm{CFU}$ (3 CFU). On the other hand, group III (treated with ketoconazole) none of the animals were infected since every animal showed $0 \mathrm{CFU}$, but one that exhibited $1 \mathrm{CFU}$. Regarding group IV (treated with 10\% ozonized theobroma formulation) infection was removed in every subjects; one of the animals showed 0 CFU.

Two days after the treatment concluded, groups I and II showed a number of microorganisms even higher than the initial value of this parameter. On the other side, in every animals of group III (treated with ketoconazole) infection was removed, since all the animals showed 0 CFU of Candida albicans. In group IV (treated with $10 \%$ ozonized theobroma oil ovules), all of the animals presented Candida concentrations lower than $10^{2}$ CFU, nevertheless there were three animals showing Candida concentrations superior to $2 \mathrm{CFU}$. Animals of group $\mathrm{V}$ (treated

\section{References}

1 Stewart DE, Whelan Cl, Fong IW, Tessler KM (1990) Psychosocial aspects of chronic, clinically unconfirmed vulvovaginitis. Obstet Gynecol 76: 852-856.

2 Cararach M, Comino R, Davi E, Marimon E, Martínez JC, et al. (2013) La vulvovaginitis candidiásica recurrente. Progresos de Obstetricia y Ginecología 56: 108-116.

3 Alemán LD, Almanza C, Fernández O (2010) Diagnosis and prevalence of vaginal infections. Revista Cubana de Obstetricia y Ginecología 36 62-103.

4 Richter SS, Galask RP, Messer SA, Hollis RJ, Diekema DJ, et al. (2005) Antifungal susceptibilities of Candida species causing vulvovaginitis and epidemiology of recurrent cases. Journal of Clinical. Microbiology 43: 2155-2162.

5 Donders G, Bellen G, Byttebier G, Verguts L, Hinoul P, et al. (2008) Individualized decreasing-dose maintenance fluconazole regimen for recurrent vulvovaginal candidiasis. American Journal of Obstetricts Gynecology 199: 613e1-613e9.

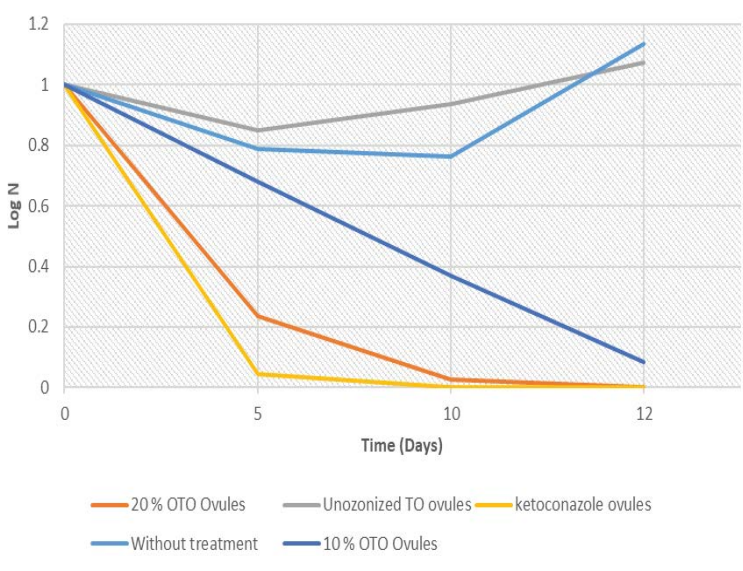

Figure 1 Microorganisms growth vs time of the different groups of rats studied. OTO ozonized theobroma oil; TO theobroma oil; $\mathrm{N}$ Microorganisms number.

with $20 \%$ ozonized theobroma oil ovules) showed a behavior exactly alike than animals of group III (Figure 1).

These results evidence that $20 \%$ ozonized theobroma oil ovules is the most effective one, since it was observed a very similar behavior compared to the group treated with ketoconazole, which is the first choice drug for the treatment of this disease.

\section{Conclusions}

Results demonstrated that a decrease of 0.7 log of the number of microorganisms occurs after 5 days of treatment with $20 \%$ ozonized theobroma oil ovules; however, there were not found signs of infection in rats after 10 days. This result was very similar to the one obtained with ketoconazole. Due to the antimicrobial activity of (20\%) ozonized theobroma oil ovules, it can be recommended its use for the treatment of vaginal Candidiasis infection.

6 Serrano-Martino MC, Chávez-Caballero M, Valverde-Conde A, Claro RM, Permán J, et al. (2003) In vitro activity of Voriconazole and three other antifungals against dermatophytes. Enfermedades Infecciosas y Microbiología Clínica 21: 484-487.

7 Bidart T (2004) Role of voriconazole and caspofungin in antifungal therapy. Revista Chilena de Infectología 21: S13-S19.

8 Lezcano I, Núñez N, Espino M, Gómez M (2000) Antibacterial Activity of Ozonized Sunflower Oil, Oleozon, Against Staphylococcus aureus and Staphylococcus epidermidis. Ozone Science and Engineering 22: 207-214.

9 Sechi LA, Lezcano I, Núñez N, Espim M, Dupré I, et al. (2001) Antibacterial Activity of Ozonized Sunflower Oil (OLEOZON). Journal of Applied Microbiology 90: 279-284.

10 Fernández I, Curtiellas V, Sánchez E, Gómez M (2006) In vitro Antimicrobial activity of ozonized theobroma oil against Candida albicans. Ozone Science and Engineering 28: 187-190.

11 Díaz M, Martínez G, Gavín JA, Meneau RI, Fernández I (2007) Study of the ozonated theobroma fat using Proton Nuclear Magnetic Resonance and microbiological analysis. Fats and Oils 58: 15-19. 
12 Díaz M, Romay C, Rojas E, González R (2008) Effect of the ozonated theobroma oil on the croton oil inflammatory response in the edema model in the mouse ear. Revista Electrónica de Clínica Veterinaria (RECVET) 18: 159.

13 Lezcano I, García G, Martínez G, Molerio J, Zamora Z, et al. (1998) Effect of ozonated cocoa butter for the treatment of vaginal candidiasis. Revista CENIC Ciencias Biológicas 29: 206-208.

14 Gunstone F, Haewood L, Padley B (1994) The lipid handbook, Chapman \& Hall, London. 14: 157

15 Lipp M, Simoneau C, Ulberth F, Anklam E, Crews C, et al. (2001)
Composition of Genuine Cocoa Butter and Cocoa Butter Equivalents. Journal of Food Composition and Analysis 14: 399-408.

16 Díaz M, Martínez G, Arteaga M, Garcés R (2006) Chemical Analysis of Ozonized Theobroma Fat. Journal of the American Oil Chemists' Society 83: 1-4.

17 EEC (1979) Control of Commercial Chemicals: The Sixth Amendment to the Directive on Dangerous Chemical Substances (79/831/EEC) Adopted by the Council of the European Communities 199.

18 Sobel JD, Muller G, McCormick JF (1985) Experimental chronic vaginal candidosis in rats. Medical Mycology 23: 199-206. 